\title{
Experimental Study on COD Composition and Electrochemical Degradation of Wastewater in Offshore Oilfields
}

\author{
Bo JING ${ }^{1, a}$, Mengying $\mathrm{YANG}^{2, \mathrm{~b}}$,Wenjuan $\mathrm{CHEN}^{1, \mathrm{c}}$, Xianqing $\mathrm{YIN}{ }^{2, \mathrm{~d}}$ \\ 1.State Key Laboratory of Offshore Oil Exploitation and Beijing Research Center of China National \\ Offshore Oil Corporation, 100027 Beijing \\ 2.College of Chemical and Environmental Engineering, Yangtze University, Jingzhou, Hubei,

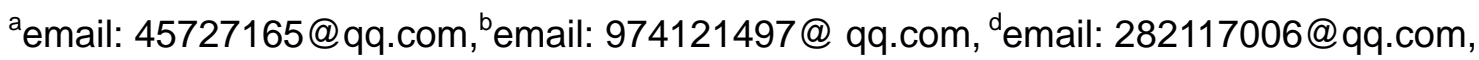 \\ *demail: jzyinxq@126.com
}

Keywords: polymer-contained oily wastewater, COD composition, residual agents, COD removal rate

\begin{abstract}
COD standard discharge of wastewater in offshore oilfields is an important part of oilfield wastewater treatment. The polymer-contained oily wastewater from oilfields in Bohai Sea was taken as the object. Combining with the wastewater treatment experiments, the major composition of COD as oils, polymer and chemical agents are researched. Under certain conditions, the two-dimensional PFR electrochemical reactor was used to treat wastewater and a linear relation between COD and concentration was established in a low concentration range. A primary study was carried out on the main factors of COD removal, the results showed that compared to the polymer, the oils were easier to be electrolyzed and the chemical agents were more difficult to be electrolyzed. The highest COD removal by electrochemical treatment of wastewater was $75.34 \%$ and the residual COD in wastewater was mainly contributed by the chemical agents and polymer which were not degraded completely.
\end{abstract}

\section{Introduction}

Wastewater treatment is a very important part of the production process in the offshore oil and gas drilling engineering. The drained index of COD content is strictly controlled on offshore fields and onshore terminals. Polymer-flooding wastewater is a complex system, which contains organic compounds dissolved in water such as emulsified crude oil, residual chemical agents and polymer from the polymer-flooding wastewater, and has characters with good thermodynamic stability, strong interfacial charge, stability of colloid particles and difficult breaking membrane ${ }^{[1-6]}$. Chen $\mathrm{Jinfu}^{[7]}$ put forward that the COD of thick oil-bearing wastewater mainly consisted of oils and apparent chemical agents. The latter mainly consisted of water-soluble organics in petroleum and various kinds of soluble organics which was added in oilfield development. Electrochemical method $^{[8-9]}$ can produce a large number of active substances such as $\mathrm{H}_{2} \mathrm{O}_{2}$ and $\bullet \mathrm{OH}$, which will cause rapid oxidation reaction and free radical chain reaction to degrade COD of the oily wastewater and reach the discharge requirement ${ }^{[10]}$. Chen $\mathrm{Wu}^{[11]}$ used electrochemical method to treat oilfield wastewater containing PAM (90 min of electrolysis, with a current of 1.0A, PAM content of $0.1 \%$, particle electrode filler using granular activated carbon of $980 \mathrm{~g}$, particle electrode size of $5 \mathrm{~mm}$, main electrode spacing of $5.0 \mathrm{~cm}$ ), the COD was decreased from $1622.9 \mathrm{mg} / \mathrm{L}$ to 64.3 $\mathrm{mg} / \mathrm{L}$.

In offshore oilfield used polymer injection way to produce crude oil. Before the water reaching wastewater treatment system, a various kinds of chemical agents will be added in the produced liquid separation processing, and part of the agents will stay in the wastewater. Due to the big property difference between the polymer and chemical regents, which have different contribution rate of COD, both polymer and chemical agents are the main contributors of COD in wastewater. In this kind of wastewater, COD composition can be dissolved to aquatic little emulsified oils, residual polymers, chemical regents and inorganic ions which can be oxidized. Because of the low 
concentration of inorganic ions such as $\mathrm{Fe}^{2+}$ and $\mathrm{S}^{2-}$ in the actual wastewater, theoretically the COD contribution can be neglected, the COD of this oilfield is mainly composed of oils, residual polymer and residual chemical agents. This paper has analyzed that the wastewater COD is mainly composed of oils, polymer and chemical agents, simultaneously studied the COD removal regularities of different forms of electrolysis wastewater, these will provide good effects in depth treatment of oilfield wastewater.

\section{Methods}

\section{Experimental instruments and chemicals}

DR1010 COD instrument (HACH)and HACH-COD preformed tube agent(15-150mg/L,), WYK-50V50AB2 dual-range DC power supply (EAST), TU-1810PC spectrophotometer, PFR electrochemical reactor (Made in lab, ).AP-P5 polymer, BHQ-05 agent, BH-04 emulsion breaker, SZ36-1 crude oils, Petroleum ether (bp 90-120 ${ }^{\circ} \mathrm{C}$ ), reticulated composite inert electrode and reticulated aluminum electrode $(120 \mathrm{~mm} \times 100 \mathrm{~mm})$.

AP-P5 is a hydrophobic association polymer, the relative molecular weight is 1200 million, the hydrolysis degree is about $26 \%$, the average nitrogen rate is about $15 \%$. BHQ-05 containing (- R $\mathrm{O}-\mathrm{R}-$ ) is a cationic water-soluble polyether compound with positive charge. The molecular formula is as follows:

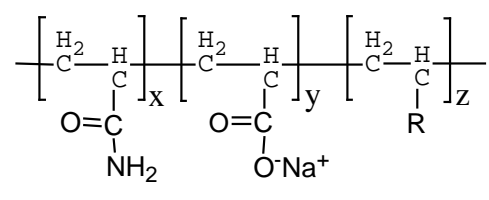

a- AP-P5

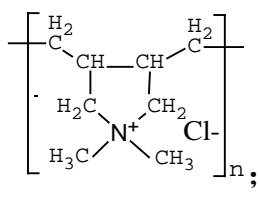

b- BHQ-05<smiles>[R]CCCOCC([R])[R]</smiles>

C- BH-04

\section{Experimental water samples}

Taking Bohai Sea terminal factory wastewater as the research object, the ion composition and content is shown in Table1. According to this data, the simulated mineralized water is formulated which had high chlorine and high salinity.

Table1 Ion content of produced wastewater in an oilfield(mg/L)

\begin{tabular}{|c|c|c|c|c|c|c|c|c|}
\hline ion composition & $\mathrm{K}^{+}, \mathrm{Na}^{+}$ & $\mathrm{Mg}^{2+}$ & $\mathrm{Ca}^{2+}$ & $\mathrm{Cl}^{-}$ & $\mathrm{SO}_{4}{ }^{2-}$ & $\mathrm{HCO}_{3}{ }^{-}$ & $\mathrm{CO}_{3}{ }^{-}$ & Total salinity \\
\hline Ion content & 3091.96 & 158.68 & 276.17 & 5436.34 & 85.29 & 311.48 & 14.21 & 9374.13 \\
\hline
\end{tabular}

According to the experimental requirements, it is necessary to accurately weigh the polymer and swell it in 5L of SZ36-1 simulated mineralized water for 5h, then dissolve 3h under the stirring speed of 350rpm. Weighing oils and controlling the speed of emulsification machine as 8000rpm, the emulsifying time as $8 \mathrm{~min}$ and the experimental temperature as 65-70 .Qfter the sample is stable ,sampling and measuring the oil content and at the same time adding quantitative BHQ-05 and $\mathrm{BH}-04$, then stirring $10 \mathrm{~min}$, sampling and measuring COD value, the electrolytic water sample has completed.

\section{Determination of oil content}

According to SY/T5329-2012 (Water quality standard and practice for analysis of oilfield injecting waters in clastic reservoirs) about the determination method of oil content in wastewater, the standard curve has been made with field standard oil samples. Using petroleum ether as the blank, the absorbance with different oil content was measured by spectrophotometer (wavelength 430nm). According to the absorbance and corresponding oil content, the curve has been drawn. Through linear match, the relationship between absorbance and oil content was obtained as follows: $\mathrm{C}_{\text {oil }}=555.56 \mathrm{~A}+1 . \mathrm{C}$ oil represents the oil content $(\mathrm{mg} / \mathrm{L})$, A represents the absorbance. The oil content in wastewater is all calculated by this method.

\section{Electrochemical experimental principle}

Using inert electrode and controllable low voltage low current dual-range DC power supply ( $U \leq 30 \mathrm{~V}, \mathrm{~A} \leq 120 \mathrm{~A}$ ), the electrochemical reaction carrying out on the surface is oxidation - reduction 
reaction.

$$
\begin{gathered}
2 \mathrm{H}_{2} \mathrm{O} \longrightarrow 2 \cdot \mathrm{OH}+2 \mathrm{H}^{+}+2 \mathrm{e} \\
\mathrm{O}_{2}+2 \mathrm{H}^{+}+2 \mathrm{e} \longrightarrow \mathrm{H}_{2} \mathrm{O}_{2} \\
\mathrm{Cl}^{+}+2 \mathrm{OH}^{-}-2 \mathrm{e} \longrightarrow \mathrm{ClO}+\mathrm{H}_{2} \mathrm{O} \\
2 \cdot \mathrm{OH} \longrightarrow \mathrm{H}_{2} \mathrm{O}+1 / 2 \mathrm{O}_{2}
\end{gathered}
$$

During the wastewater electrolysis process, free-radicals such as $\cdot \mathrm{OH}, \mathrm{HO}_{2} \cdot{ }^{\cdot} \mathrm{O}_{2}$ and other substances as $\mathrm{ClO}^{-}, \mathrm{O}_{3}$ and $\mathrm{H}_{2} \mathrm{O}_{2}$ are produced. These free-radicals can lead to the irreversible electrochemical oxidation degradation reaction of polymer and emulsified oil. The obtained $\cdot \mathrm{OH}$ radicals can react with residual polymer rapidly following oxidation reaction and free radical chain reaction. In this case the free-radical $\cdot \mathrm{OH}$ can cause partial or total organic matter degradation. Presenting with the reaction between $\cdot \mathrm{OH}$ and polymer, besides the above reaction, organic free radicals as RCOO- and RCO- are produced when PAM molecular bond rupture, these radicals could react with PAM molecular and cause its degradation. The other case is PAM molecular is directly oxidized to straight chain or small molecule or acrylamide monomer or acrylic acid or other small groups, at the same time, some small molecules or groups which can be further degraded into $\mathrm{CO}_{2}, \mathrm{H}_{2} \mathrm{O}, \mathrm{NO}_{3}$ and $\mathrm{N}_{2}$ et al., so as to achieve the effect of fully degrading the polymer. The equation of PAM degradation is as follows:

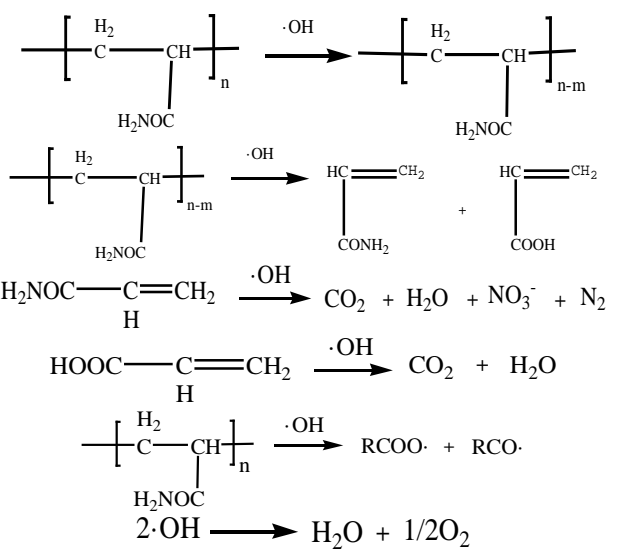

The size of electrochemical reactor is $260 \mathrm{~mm}$ (width) $\times 250 \mathrm{~mm}$ (length) $\times 200 \mathrm{~mm}$ (depth) and the effective reaction volume is $4.3 \mathrm{~L}$. Designing PFR reactor ${ }^{[6]}$ for the wastewater degradation treatment, the electrolysis conditions are electrolysis time of 30-40 min, output current of 3-4 A, plate spacing of $6-8 \mathrm{~cm}$ and area-volume ratio of $2 / 19 \mathrm{~cm}^{2} / \mathrm{mL}$. Using two pairs of electrodes, the composite inert mesh electrode plate is used for anode and the mesh aluminum electrode plate is used for cathode.

\section{Results and discussions}

\section{Standard curves of different wastewater COD}

1) Standard curve for the COD contribution of oils

The content of oils in terminal factory production wastewater is about $50 \mathrm{mg} / \mathrm{L}$. The oily wastewater with different oil content was prepared by using deionized water. Measuring the COD value and actual oil content, according to the measured oil content and the corresponding COD, the curve has been drawn. Through linear match, the relationship between oil content and COD value was obtained as follows: $\mathrm{COD}_{\text {oil }}=6.8866 \mathrm{C}_{1}-0.6008, \mathrm{R}^{2}=0.9969 . \mathrm{C}_{1}$ represents the mass concentration of oils (mg/L). Fig.1(a).

2) Standard curve for the COD contribution of AP-P5 polymer

The content of polymer in terminal factory production wastewater is about $200 \mathrm{mg} / \mathrm{L}$. The polymer-contained wastewater with different polymer content was prepared by using deionized water. Measuring the COD value and drawing the curve. Through linear match, the relationship between the polymer content and COD value was obtained as follows: COD polymer $=0.8498 \mathrm{C}_{2}+$ 
2.8189, $\mathrm{R}^{2}=0.9999 . \mathrm{C}_{2}$ represents the mass concentration of polymer (mg/L).It shows that the polymer content is linear with COD value in a certain concentration range. Fig.1(b).

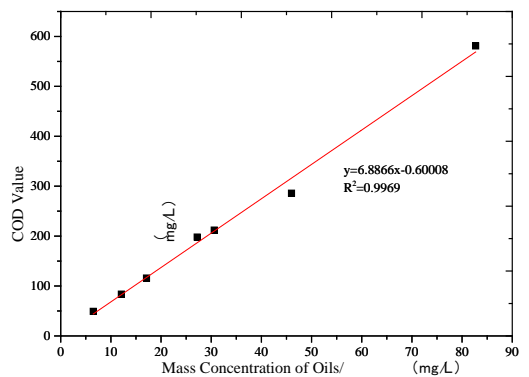

(a) oils

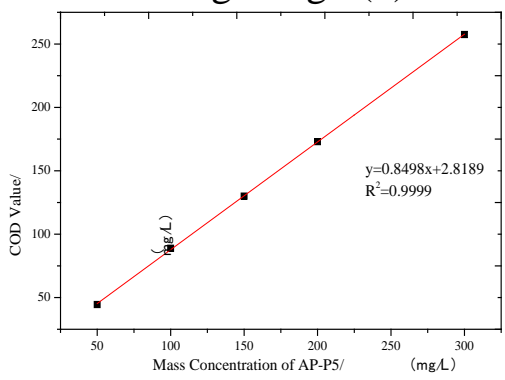

(b) AP-P5

Fig.1 Variation trend of the mass concentration and COD value

3) Standard curve for the COD contribution of chemical agents

On the field, the adding amount of BH-04 is $280 \mathrm{mg} / \mathrm{L}$ and BHQ-05 is $300 \mathrm{mg} / \mathrm{L}$. In the experimental study, these above two agents were added in this ratio. Calculating the total amount of added agents, the COD value was determined and the standard curve was drawn. Through linear match, the relationship between the agent content and COD value was obtained as follows: COD agent $=0.8733 \mathrm{C}_{3}+0.5, \mathrm{R}^{2}=0.9999 . \mathrm{C}_{3}$ represents the mass concentration of agent $(\mathrm{mg} / \mathrm{L})$.It shows that the residual agent content is linear with COD value in a certain concentration range. Fig.2(b)

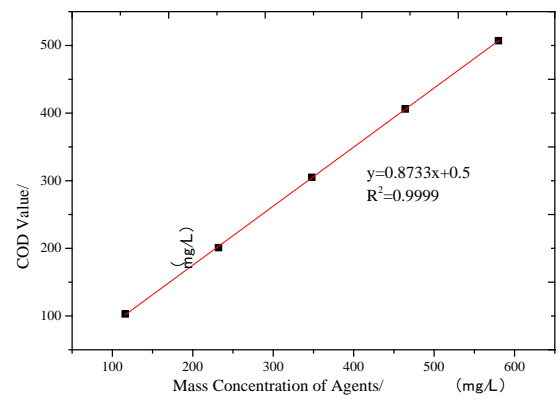

Fig.2 Variation trend of the mass concentration of agents and COD value

\section{The main factors affecting the COD removal of wastewater}

\section{Effect of salinity on the removal rate of COD}

The degree of salinity affects the conductivity of solution, and the higher salinity will be with the better conductivity of the solution. The salinity of offshore oilfields is generally distributed in the range of $5000 \sim 10000 \mathrm{mg} / \mathrm{L}$. The experiments were used 5 groups water samples with different salinities. The content of polymer was $200 \mathrm{mg} / \mathrm{L}$ and the determination results with different salinity are shown in Table 2.

Table.2 Electrochemical testing results of water samples with different salinity

\begin{tabular}{c|ccccc}
\hline Classification & 1 & 2 & 3 & 4 & 5 \\
\hline Salinity $(\mathrm{mg} / \mathrm{L})$ & 5000 & 6000 & 7000 & 8000 & 9500 \\
Oil content $(\mathrm{mg} / \mathrm{L})$ & 37.33 & 35.72 & 36.44 & 35.11 & 39.56 \\
COD before electrolysis (mg/L) & 460 & 407.5 & 434.5 & 411 & 478 \\
COD after electrolysis (mg/L) & 28.8 & 27.5 & 12 & 42 & 43.25 \\
COD oil removal rate (\%) & 100 & 100 & 100 & 100 & 100 \\
COD polymer removal rate (\%) & 83.33 & 84.08 & 93.05 & 75.69 & 74.97 \\
COD total removal rate (\%) & 93.74 & 93.25 & 97.24 & 89.78 & 90.95 \\
\hline
\end{tabular}

After the electrochemical treatment, the water samples were clear and transparent, and all of their absorbance was 0 when measuring their oil content. This shows that the water samples are not oily after the electrolysis treatment which means the removal rate of oils is $100 \%$, and the polymer contributed all of COD.

$$
\begin{aligned}
& \text { COD polymer removal rate }=1-\mathrm{COD}_{\text {after electrolysis }} /(200 \times 0.8498+2.8189) \times 100 \% \\
& \mathrm{COD} \text { total removal rate }=1-\mathrm{COD}_{\text {after electrolysis }} / \mathrm{COD}_{\text {before electrolysis }} \times 100 \%
\end{aligned}
$$


The table 2 shows that with increasing of salinity, the total COD removal rate is steady consistent and the trend of the contribution to COD value of emulsified oil and polymer is unobvious. The salinity of the wastewater has less affects in electrochemical treatment. Before electrolysis, the COD is all contributed by oils and polymer. According to the standard curve of polymer, the COD contributed by polymer can be calculated, and then we can get the actual oil concentration of wastewater.

\section{Effect of the concentration of the polymer on the removal rate of COD}

5 groups of water samples with different concentration of the polymer were carried out in the experiments. The salinity was $9374 \mathrm{mg} / \mathrm{L}$ and the determination results are shown in Table 3.

Table.3 Electrochemical testing results of water samples with different concentration of polymer

\begin{tabular}{c|ccccc}
\hline Classification & 1 & 2 & 3 & 4 & 5 \\
\hline C polymer (mg/L) & 100 & 150 & 200 & 250 & 350 \\
C Oil (mg/L) & 42.8 & 49.3 & 55.7 & 61.8 & 59.3 \\
COD before electrolysis (mg/L) & 367 & 469.5 & 585 & 675 & 745 \\
COD after electrolysis (mg/L) & 44 & 57 & 50 & 75.25 & 61.75 \\
COD oil removal rate (\%) & 100 & 100 & 100 & 100 & 100 \\
COD polymer removal rate (\%) & 49.89 & 56.25 & 71.06 & 65.04 & 79.43 \\
COD total removal rate (\%) & 88.01 & 87.86 & 91.45 & 88.85 & 91.71 \\
\hline
\end{tabular}

After the electrochemical treatment, when measuring the oil content, the results showed that all absorbance was 0 , the removal rate of oils was $100 \%$ and the polymer contributed all of COD.
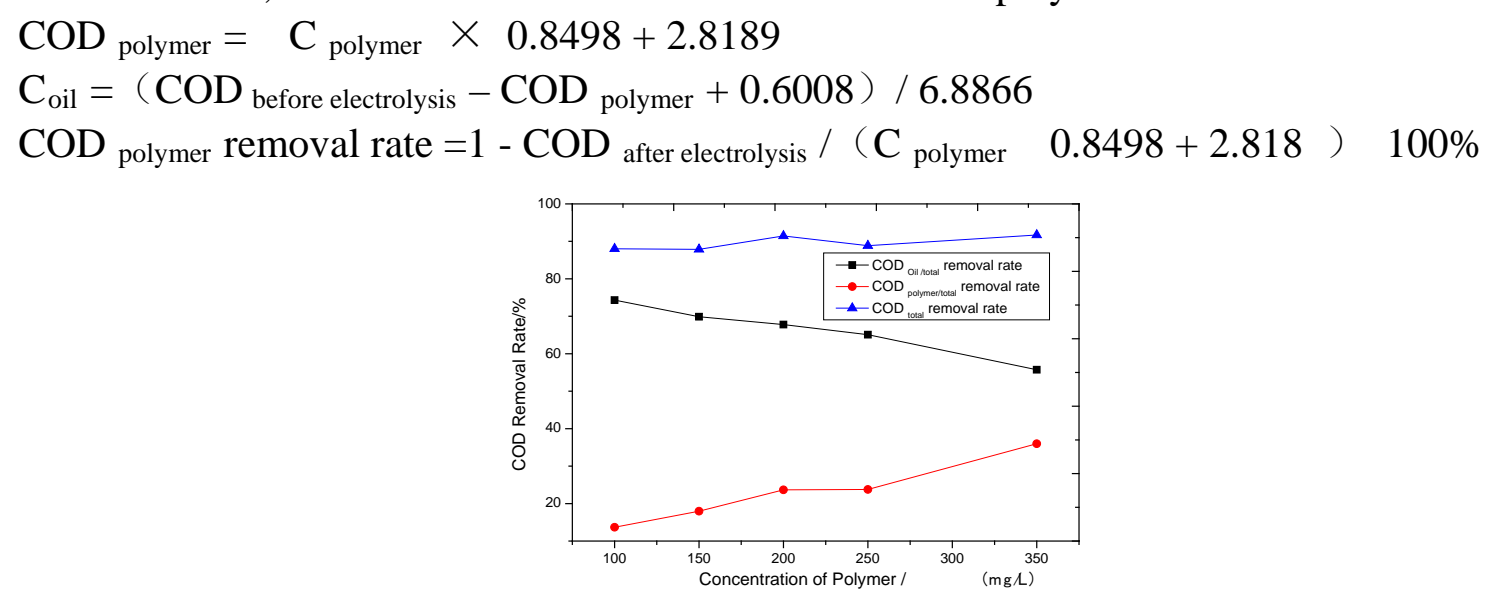

Fig.3 Variation trend of the contribution of oils and polymer in the total COD removal rate under different concentration of polymer

$\mathrm{COD}$ total removal rate $=\mathrm{COD}$ oil/total removal rate $+\mathrm{COD}$ polymer/total removal rate

COD polymer/total removal rate $=\left(C O D_{\text {polymer }}-\mathrm{COD}_{\text {after electrolysis }}\right) / \mathrm{COD}_{\text {before electrolysis }} \times 100 \%$

The contribution of oil and polymer in the total COD removal rate was calculated individually. It is shown in Fig.4 that with increasing concentration of the polymer, the total COD removal rate is steady consistent and the contribution rate of polymer gradually increases which means the polymer is easier to be degraded.

\section{Effect of the agent on the removal rate of COD}

BHQ-05 and BH-04 were used to simulate the agent content of oilfield wastewater. The concentration of BHQ-05 was $300 \mathrm{mg} / \mathrm{L}$, the concentration of BH-04 was $280 \mathrm{mg} / \mathrm{L}$, and the salinity was $9374 \mathrm{mg} / \mathrm{L}$. The results in Table 4 show that the agents contribute greater for COD value and are more difficult to be degraded.

Table.4 Changes of COD value before and after electrolysis

\begin{tabular}{cccc}
\hline Index & COD before electrolysis /mg/LCOD after electrolysis /mg/Lremoval rate of agents $/ \%$ \\
\hline Testing results & 497.5 & 305 & 38.69 \\
\hline
\end{tabular}

COD removal experiment of simulated field water samples

Field water samples contained oils, polymer and residual agents. The experiments used 5 groups 
of different water samples, the salinity was $9374 \mathrm{mg} / \mathrm{L}$, the concentration of oil was around $60 \mathrm{mg} / \mathrm{L}$, the concentration of BHQ-05 was $300 \mathrm{mg} / \mathrm{L}$, the concentration of BH-04 was $280 \mathrm{mg} / \mathrm{L}$. The results are shown in Table 5.

Table.5 Electrochemical testing results of water samples with different concentration of polymer

\begin{tabular}{c|ccccc}
\hline Classification & 1 & 2 & 3 & 4 & 5 \\
\hline $\mathrm{C}_{\text {polymer }}(\mathrm{mg} / \mathrm{L})$ & 100 & 150 & 200 & 250 & 350 \\
$\mathrm{C}_{\text {Oil }}(\mathrm{mg} / \mathrm{L})$ & 43.89 & 56.79 & 52.44 & 59.89 & 58.20 \\
COD before electrolysis $(\mathrm{mg} / \mathrm{L})$ & 861 & 1020 & 1040 & 1160 & 1230 \\
COD after electrolysis $(\mathrm{mg} / \mathrm{L})$ & 239.75 & 252.50 & 270.00 & 286.00 & 355.50 \\
COD oil removal rate (\%) & 100 & 100 & 100 & 100 & 100 \\
COD polymer removal rate (\%) & 49.89 & 56.25 & 71.06 & 65.04 & 79.43 \\
COD agent removal rate (\%) & 61.39 & 61.44 & 56.61 & 58.43 & 42.03 \\
COD total removal rate (\%) & 72.15 & 75.25 & 74.04 & 75.34 & 71.10 \\
\hline
\end{tabular}

After the electrochemical treatment, the water samples were extracted by petroleum ether, the results showed that all absorbance was 0 , the removal rate of oils was $100 \%$ and the residual polymer and agents contributed all of COD. Due to the concentration of residual polymer and agents not being measured accurately, the removal rate of COD polymer in Table 5 is the same as in Table 3 and the calculation method of each data is consistent with the above method.

We can know from table 5, under the condition of electrochemical treatment, the polymer content has less effect on the COD removal, but it has synergy with agents. This synergy makes the agents more difficult to be degraded when polymer content increases in the process of electrochemical treatment, and the COD removal of agent changes from $61.44 \%$ to $42.03 \%$.

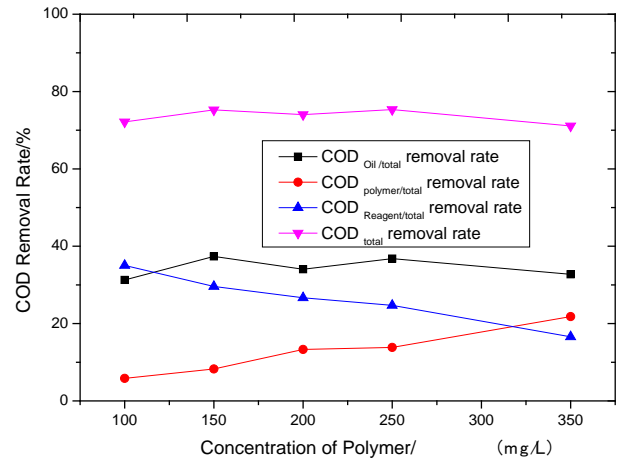

Fig.4 Under different concentration of the polymer the variation trend of the contribution of oil and polymer and agent in the total COD removal rate

Figure.4 is a comparison trend between the COD removal of three components and the total COD removal of the wastewater when treated by electrochemical method, in which the total COD removal rate is $71 \sim 75 \%$ and the changing scope is relatively stable. With the increase of the polymer content, the oil is easier to be degraded and contributes stable COD removal rate in the total COD removal rate. The contribution of polymer in total COD removal rate gradually increases while the contribution of agents decreases, which indicates the agents become more difficult to be degraded. The possible reason could be: with the relatively stable content of oils and residual agents, when the polymer content in the wastewater was increasing, the polymer concentration around the electrode plates also increased. This phenomenon affected and hindered the degradation of residual agents in a certain extent, but made no influence on oil degradation. Finally it led to a gradually decrease of the agents contribution in the total COD removal rate.

\section{Conclusions}

On offshore oilfields, the COD value in polymer-contained oily wastewater is mainly dissolved to aquatic little emulsified oils, polymer and residual chemical agents and the content is linear with COD value in a low concentration range. The salinity of the wastewater makes less affect in 
electrochemical treatment. Emulsified oil and polymer are easily degradable. Using two-dimensional PFR electrochemical reactor to degrade oily and polymer-contained wastewater, the COD removals, after 30-40 min of electrolysis, with a current of 3-4 A, electrode spacing of $6-8 \mathrm{~cm}$, area-volume ratio of $2 / 19 \mathrm{~cm}^{2} / \mathrm{mL}$, composite inert mesh electrode plate of anode, mesh aluminum electrode plate of cathode, are $71-75 \%$. The agents difficult to be degraded are the major contributor of COD in treated wastewater. With the increase of the polymer content, it's more difficult for the dislodge of the agents. Therefore, improving the utilization rate of field agents to reduce the residual agents in wastewater is an effective measure to reduce the difficulty of the wastewater treatment.

\section{Acknowledgements}

The authors of this work wish to gratefully acknowledge the financial support from the Open Fund of State Key Laboratory of Offshore Oil Exploitation (Project No: CCL2015RCPS0221RNN )

\section{References}

[1] Adriana M. Z. R., Carlos A. M. \& Djalma R. S. Application of electrochemical technology for removing petroleum hydrocarbons from produced water using a DSA-type anode at different flow rates[J]. Fuel Processing Technology, 2010 ,89, 531-534.

[2] Min Duan, He Wang, Jiang Zhang . Analysis of Operational Rate and Problem of Produced Water System in LD 10-1 Oilfield[J].. China Offshore oil and Gas, 2010 22(6), 420-423.

[3]TaoJiang,Jian Fang, Study on the flocculants for treating polymer-bearing wastewater in SZ36-1 Oilfield[J].. Industrial Water Treatment, 2012 32(7), 81-83.

[4] Minhuan Shen,Jingben Wang. Study on the wastewater treatment of polymer flooding produced water in Bohai oilfield[J].. Industrial Water Treatment, 2009 29(9), 69-71.

[5] Xianqing Yin, Jian Zhang, Bo Jing. Effect of polymer content of polymer-flooding sewage water on the equipments for wastewater treatment. Chinese Journal of Environmental Engineering[J]., 6(10), 2012 3499-3502.

[6] Jian Zhang. A kind of suitable for sea oil-field of containing and gathering sewage efficiently treatment[J].. Oil-gas field surface engineering, 2013 32(8), 9-10.

[7] Jinfu Chen , Discussion on the upgraded standard treatment technology of oil-bearing wastewater in oilfields[J]. Industrial Water Treatment, 2013 33(2), 70-72.

[8] Wu Chen, Bo Jing, Jiang Zhang. Study on the aggregative properties of polymer-flooding Oil-bearing wastewater[J]. Industrial Water Treatment, 2012 32(3),77-80.

[9] Jéssica H. B. R., Maésia M. S. G., Nedja S. F. Application of electrochemical oxidation as alternative treatment of produced water generated by Brazilian petrochemical industry[J].. Fuel Processing Technology, 2012 96, 80-87.

[10]Wu Chen,Ping Mei. Electrochemical techniques for environmental pollution control[M]. Beijing Petroleum Industry Press, China. 2013

[11] Wu Chen, Chanzhu.Yang, Ping Mei. Treatment of Wastewater Containing Polyacrylamide Using Three Dimensional Electrodes[J].. Wuhan University Journal of Natural Sciences, 2007 12(2), 353-360. 